\title{
Ectopic Thyroid Tissue in Submandibular Region in Pediatric Patient: A Case Report
}

\section{Rohita Bajracharya, Heempali Dutta}

Department of Otorhinolaryngology \& Head and Neck Surgery, Maharajgunj Medical Campus, Ganesh Man Singh Memorial Academy of ENT, Head \& Neck Studies, Tribhuvan University Teaching Hospital, Institute of Medicine, Maharajgunj, Kathmandu, Nepal

\section{Corresponding author:}

\section{Rohita Bajracharya, MBBS}

Department of Otorhinolaryngology \& Head and Neck Surgery, Maharajgunj Medical Campus, Ganesh Man Singh Memorial Academy of ENT, Head \& Neck Studies, Tribhuvan University Teaching Hospital, Institute of Medicine, Maharajgunj, Kathmandu, Nepal

Email: rohitabajracharya@iom.edu.np

Submitted : Aug 6, 2020

Accepted : Nov 19, 2020

\begin{abstract}
Normal anatomical location of thyroid gland is anterior to trachea and larynx. Ectopic thyroid is rare presentation. Ectopic thyroid tissue in submandibular region is even more rare. This article reports a case of five year old child who presented with swelling in left submandibular region which was later diagnosed to be an ectopic thyroid gland with no thyroid tissue in thyroid bed. Although rare, physician should consider possibility of ectopic thyroid in patient presenting with submandibular mass. Ultrasonography should always be performed to confirm presence of normal thyroid gland if surgical excision is planned.
\end{abstract}

Keywords

Ectopic thyroid, submandibular region, thyroglossal duct, thyroid gland

\section{INTRODUCTION}

$\mathrm{E}$ ctopic thyroid gland is defined as a mass of benign thyroid tissue located in any site other than anterolateral to second, third and fourth tracheal rings. ${ }^{1}$ It is a rare developmental anomaly and is usually found in the midline such as lingual, sublingual, in thyroglossal duct cyst, prelaryngeal, intralaryngeal or intratracheal. Non midline sites are even more rare such as submandibular, intrathoracic (mediastinal, lung, heart), adrenal glands, duodenum, pancreas and intestine. ${ }^{2}$

The prevalence of ectopic thyroid tissue is about 1 per 100,000-300,000 people and are found commonly in females. ${ }^{2}$ Only 1 to $3 \%$ of all ectopic thyroids are located in the lateral neck. ${ }^{3}$ In $70 \%$ of patients with ectopic thyroid there is no other eutopic thyroid tissue and the removal of ectopic thyroid result in severe hypothyroidism. ${ }^{4}$ Only few such cases with non midline ectopic thyroid have been reported in literature worldwide. Hence, although extremely rare ectopic thyroid should be considered in submandibular mass to avoid accidental removal. We report a rare case of ectopic thyroid in left submandibular region in five year old girl.

\section{CASE PRESENTATION}

A 5-year old girl presented to a local hospital in Chitwan district with complaint of mass in left submandibular region which was first noticed by 


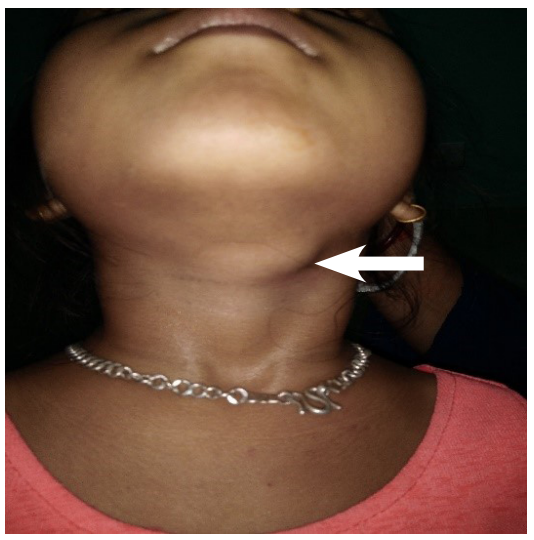

Fig 1. Swelling in the left submandibular region
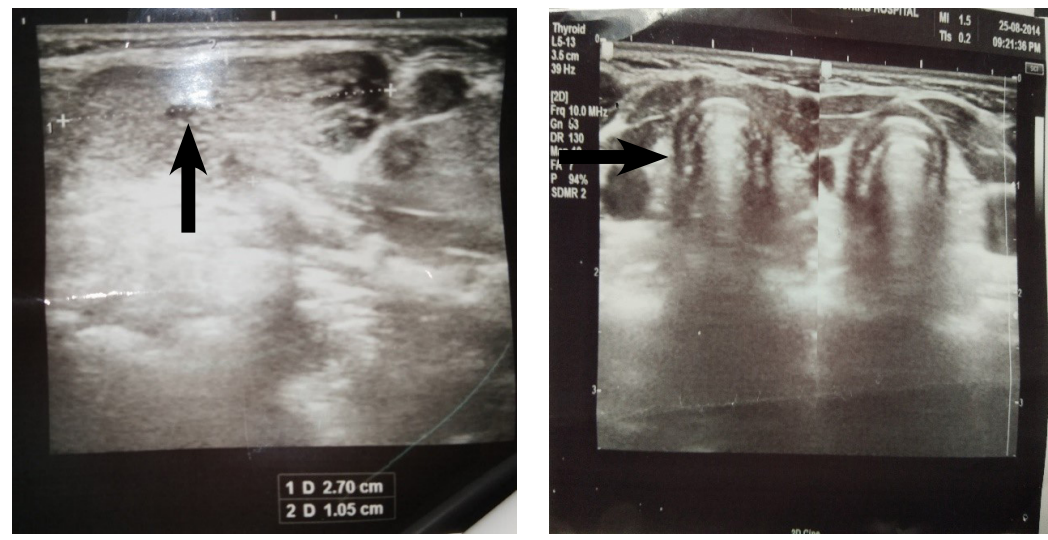

Fig 2a. Ultrasonography showing heteroechoic lesion with few anechoic areas in left submandibular region; Fig 2b. Absent eutopic thyroid her mother for three months. The mass was initially painless however there was pain since three days prior to presentation and was static in size (Figure 1). She was treated there as reactive lymphadenitis and was prescribed a week course of Cloxacillin and Paracetamol. However the size didn't reduce so she came to out patient clinic of Ear, Nose and ThroatHead \& Neck Surgery Department in Tribhuvan University Teaching Hospital. On examination, there was approximately $2 \times 1 \mathrm{~cm}$ single swelling in left submandibular region which was non tender, smooth, well defined and no movement could be appreciated on deglutition or tongue protrusion. There was no cervical lymphadenopathy. She was calm and pulse rate was $80 \mathrm{~b} / \mathrm{min}$. She was in the $95^{\text {th }}$ percentile for weight. She underwent neck

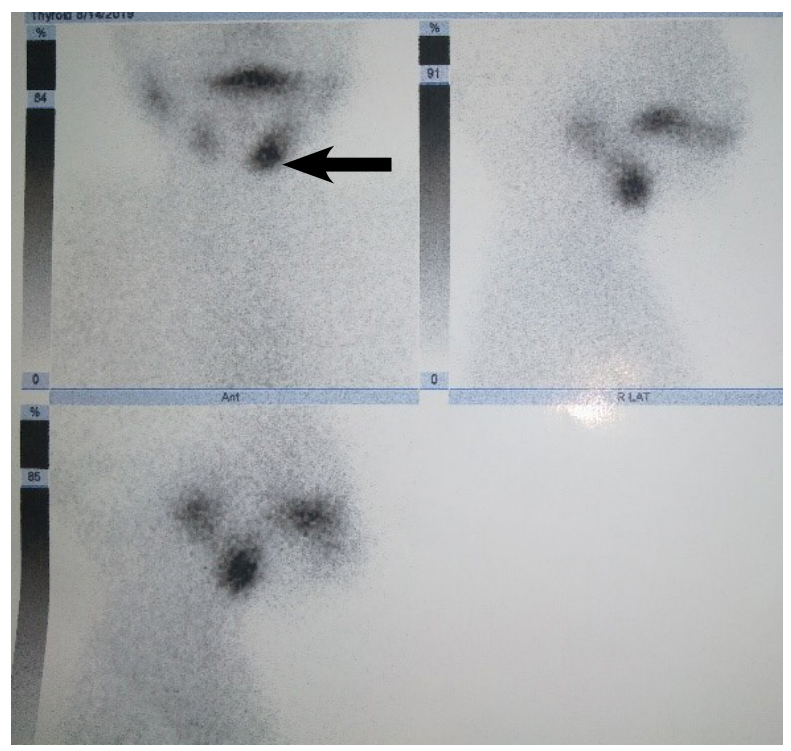

Fig 3. $99 m$ Tc Pertechnetate thyroid scintigraphy showing focus of tracer uptake in left submandibular region and no functioning thyroid tissue in thyroid bed in the left submandibular region ultrasonography which showed approximately $2.7 \times 1 \mathrm{~cm}$ well defined heteroechoic lesion in left submandibular region with few anechoic area within and absence of thyroid in normal location (Figure 2). Thyroid function test showed subclinical hypothyroidism with $\mathrm{fT}_{3}$ level $7.47 \mathrm{pmol} / \mathrm{L}, \mathrm{fT}_{4}$ level $15.4 \mathrm{pmol} / \mathrm{L}$ and TSH level of $24.7 \mu \mathrm{lU} / \mathrm{ml}$. Fine needle aspiration cytology of left submandibular mass was performed and revealed sheets of benign follicular cells and colloid laden macrophages in background of thin and thick colloid with features suggestive of ectopic thyroid. The 99m Tc Pertechnetate thyroid scintigraphy was performed that showed focus of tracer uptake in left Submandibular region suggestive of ectopic thyroid gland in left submandibular region with no evidence of functioning thyroid tissue in thyroid bed (Figure 3). Hence diagnosis of ectopic left submandibular thyroid with absent normal thyroid was confirmed and she was prescribed levothyroxine and is on regular follow up initially monthly and now in every 6 months. The size of the swelling is static and her Thyroid Function Test levels are within normal range.

\section{DISCUSSION}

Thyroid gland is the first endocrine gland to develop during embryonic development. ${ }^{4}$ It develops from a median and two lateral anlage. At around fifth week of gestation, the thyroid gland descends through the thyroglossal duct as an invagination in the foramen cecum from the base of the tongue to the front of the anterior tracheal wall and reaches its final position in the seventh week. ${ }^{5}$

The cause of ectopic thyroid remains unclear however thyroid transcription factor 2 mutation which is required for downward migration of the gland is thought to be a possible mechanism. ${ }^{6}$ In rare cases, an abnormal migration with cell rests deposited laterally or a failure of the lateral anlage to fuse with the median anlage may result in the development of lateral thyroid tissue. ${ }^{7}$ A neck mass 
in a pediatric patient has a broad differential including congenital abnormalities, inflammatory lesions and malignant lesions. Rate of malignancy in ectopic thyroid is similar to normally positioned thyroid. ${ }^{8}$ Work-up of neck masses is challenging in children as diagnostic tests such as fine-needle aspiration and magnetic resonance imaging is difficult in pediatric patient and may need sedation. Most of the reported cases of lateral ectopic thyroid (76\%) were diagnosed after surgical removal resulting in hypothyroidism. ${ }^{3}$ Hence unless suspected or proven carcinoma excision should not be done. No treatment is necessary for an asymptomatic ectopic thyroid with normal thyroid function and cytology. Fine-needle aspiration is sufficient to monitor its progress. $^{9}$

\section{CONCLUSION}

Lateral ectopic thyroid is a rare condition. However, physician should consider possibility of ectopic thyroid in patient presenting with submandibular mass. Treatment may be conservative with hormone replacement and surgery for only those showing signs of upper airway obstruction or malignant changes. Ultrasonography should mandatorily be performed to confirm presence of normal thyroid gland if surgical excision is planned.

\section{CONFLICT OF INTEREST}

None declared.

\section{REFERENCES}

1. Ibrahim NA, Fadeyibi IO. Ectopic thyroid: etiology, pathology and management. Hormones. 2011;10(4):261-269.

2. Noussios G, Anagnostis P, Goulis DG, Lappas D, Natsis K. Ectopic thyroid tissue: anatomical, clinical, and surgical implications of a rare entity. Eur J Endocrinol. 2011;165(3):375-382.

3. Prado H, Prado A, Castillo B. Lateral Ectopic Thyroid: A Case Diagnosed Preoperatively. Ear Nose Throat J. 2012;91(4):E14-E18.

4. AJ Bolouri, M Basirat, Z Dalirsani, RZ Mahmoodabadi, J Salehinejad. Ectopic thyroid in submandibular and sublingual region: report a case and review of literatures. Journal of Applied Sciences.2011; 11(5): 892-898.

5. Rosen, R. and Sapra, A., 2020. Embryology, Thyroid. [online] Ncbi. nIm.nih.gov. Available at: <http://www.ncbi.nlm.nih.gov/books/ NBK551611/> [Accessed 9 July 2020].

6. Van Vliet G. Development of the thyroid gland: lessons from congenitally hypothyroid mice and men. Clin Genet. 2003;63(6):445-455.

7. Bersaneti JA, Silva RDP, Ramos RRN, de Medeiros Matsushita M, Souto LRM. Ectopic Thyroid Presenting as a Submandibular Mass. Head Neck Pathol. 2010;5(1):63-66.

8. Adelchi C, Mara P, Melissa L, De Stefano A, Cesare M. Ectopic thyroid tissue in the head and neck: a case series. BMC Res Notes. 2014;7(1):1-6.

9. Maki AC, Foster MB, Bond SJ. Lateral pediatric ectopic thyroid. The Laryngoscope. 2013;123(2):524-527. 